\title{
Energetic and economic analysis of vapour compression refrigeration systems applied in different temperature ranges
}

\author{
Zhili Sun, Qi Cui, Qingzhao Liu, Caiyun Wang, Jiamei Li and Lijie Yang \\ Tianjin Key Laboratory of Refrigeration Technology, Tianjin University of Commerce, Tianjin, People's Republic of China
}

\begin{abstract}
To determine the suitable vapour compression refrigeration system for different temperature ranges, this paper established thermodynamic models for a single-stage vapour compression refrigeration system with an economiser (SSRS+E), a two-stage vapour compression refrigeration system (TSRS), and a cascade vapour compression refrigeration system (CRS) and conducted an energetic and economic analysis of it. The results show that compared with TSRS, SSRS+E can save energy by $13.6 \%$ and $7.1 \%$, in the evaporating temperatures of $-20^{\circ} \mathrm{C}$ and $-25^{\circ} \mathrm{C}$, respectively. R744/R717 CRS is superior to TSRS in terms of energy consumption and refrigeration unit investment costs. Compared with TSRS, R744/ R717 CRS can save energy by $14.1 \%$ and $18.8 \%$, in the evaporating temperatures of $-45^{\circ} \mathrm{C}$ and $-50^{\circ} \mathrm{C}$, respectively. Based on the energetic and economic analysis, $\mathrm{SSRS}+\mathrm{E}$ is recommended for use above the evaporating temperature of $-25^{\circ} \mathrm{C}$. TSRS is recommended for use in the evaporating temperature range of $-45^{\circ} \mathrm{C}$ to $-25^{\circ} \mathrm{C}$, and $\mathrm{R} 744 / \mathrm{R} 717 \mathrm{CRS}$ is recommended for use below the evaporating temperature of $-45^{\circ} \mathrm{C}$.
\end{abstract}

KEYWORDS Vapour compression refrigeration system; thermodynamic models; energetic analysis; economic analysis CONTACT Zhili Sun sunzhili@tjcu.edu.cn

Received 30 March 2020

$\begin{array}{ll}\text { Nomenclature } & \\ h & \text { specific enthalpy }(\mathrm{kJ} / \mathrm{kg}) \\ k & \text { polytropic index } \\ m & \text { mass flow rate }(\mathrm{kg} / \mathrm{s}) \\ p & \text { pressure }(\mathrm{MPa}) \\ Q & \text { heat exchange capacity }(\mathrm{kW}) \\ q_{v h} & \text { theoretical displacement of compressor }\left(\mathrm{m}^{3} / \mathrm{h}\right) \\ s & \text { specified entropy }\left(\mathrm{kJ} /\left(\mathrm{kg} \cdot{ }^{\circ} \mathrm{C}\right)\right) \\ T / t & \text { temperature }\left({ }^{\circ} \mathrm{C}\right) \\ v & \text { specific volume }\left(\mathrm{m}^{3} / \mathrm{kg}\right) \\ W & \text { input power }(\mathrm{kW}) \\ \text { Subscripts } & \\ 1,2,3 \ldots & \text { state point of refrigerant } \\ C H X & \text { cascade heat exchanger } \\ E c o & \text { economiser } \\ e & \text { evaporation } \\ h & \text { high-temperature cycle } \\ l & \text { low-temperature cycle } \\ m & \text { middle } \\ v & \text { volume } \\ \text { Acronyms } & \\ \text { COP } & \text { coefficient of performance } \\ \text { CHX } & \text { cascade heat exchanger } \\ \text { CRS } & \text { cascade vapour compression refrigeration system } \\ \text { HTC } & \text { high-temperature cycle } \\ \text { HTS } & \text { high-temperature stage } \\ \text { LTC } & \text { low-temperature cycle } \\ \text { LTS } & \text { low-temperature stage } \\ \text { SSRS }+\mathrm{E} & \text { single-stage vapour compression refrigeration system with } \\ \text { TSRS } & \text { economiser } \\ \text { HCFCs } & \text { two-stage vapour compression refrigeration system } \\ & \\ & \text { hydrochlorofluorocarbons } \\ & \end{array}$

\section{Introduction}

In scientific research and industrial production, refrigeration temperature ranges are often divided into two parts: ordinary cold and cryogenic. According to the 13th International Congress of Refrigeration (1971), the ambient temperature to $120 \mathrm{~K}\left(-153.15^{\circ} \mathrm{C}\right)$ is defined as ordinary cold temperature range, where vapour compression refrigeration is the most commonly used method to provide cooling or freezing for domestic, commercial, and industrial application (She et al., 2018; Steven Brown and Domanski, 2014).

Based on the different lowest refrigeration temperatures, the structure of vapour compression refrigeration system has different forms: single-stage, twostage, cascade, and multi-cascade (Baakeem et al., 2018). The lowest temperature that a system form can produce is limited and constrained by the efficiency of compressor operation. Essentially, it is closely related to the refrigerants used in the system.

The choice of refrigerants depends mainly on their operating pressure, environmental protection characteristics, and thermophysical properties (Devecioğlu and Oruç, 2015), among which environmental protection characteristics are mandatory. Due to the destruction of ozone layer by hydrochlorofluorocarbons (HCFCs) and the impact of hydrofluorocarbons (HFCs) on the global greenhouse effect, relevant international conventions and legislations are restricting the use of them (Polonara et al., 2017; Heath, 2017). Consequently, as HCFCs and HFCs phase out, natural refrigerants are gaining widespread attention and applications 
(Abas et al., 2018; Kasaeian et al., 2018; Ciconkov, 2018), with $\mathrm{NH}_{3}$ (R717) (Patel et al., 2019), $\mathrm{CO}_{2}$ (R744) (Gullo et al., 2018; Sawalha et al., 2017), and hydrocarbons (HCs) (Bobbo et al., 2018) considered to be the most promising. Therefore, R717, R744, and R170 (HCs) are selected as refrigerants studied in this paper, which makes the research results more applicable.

Ordinary cold temperature range from $-75^{\circ} \mathrm{C}$ to $0^{\circ} \mathrm{C}$ is often used for food freezing and cold storage, cold chain, aerospace refrigeration, blood banks, etc. Single-stage vapour compression refrigeration system (SSRS), twostage vapour compression refrigeration system (TSRS), and cascade vapour compression refrigeration system (CRS), are typical vapour compression refrigeration systems often used to operate at such a temperature range. SSRS is often used in a relatively high temperature range. In practical applications, in order to improve performance of SSRS, it is usually used in conjunction with an economiser based on the intermediate gas-injection technology in the compression process (Choi et al., 2018; Wang et al., 2018; Wang et al., 2015), which is called single-stage vapour compression refrigeration system with economiser $(\mathrm{SSRS}+\mathrm{E})$. In order to produce lower temperature than $\mathrm{SSRS}+\mathrm{E}$, two compressors are required to share the corresponding compression ratio together, which leads to a relatively high operating efficiency of the compressor of each stage, and this is called TSRS. CRS can also produce lower temperatures than SSRS+E, but the principle is different from that of TSRS. CRS has two cycles and each of them uses a different refrigerant with different normal boiling points. It makes their pressures and the corresponding efficiency of compressor operate within an appropriate range. However, the cost of producing lower temperatures is that the system is more complex and the investment for the system is greatly increased.

Energy efficiency and economy are two important aspects of evaluating the quality of refrigeration systems. For engineers, in order to meet the refrigeration needs of a certain field, a reasonable design of refrigeration units is extremely important. Within a relatively high temperature range, SSRS+E and TSRS have a cross-temperature range, where both systems can produce the same temperature and meet the same refrigeration requirements. In a relatively low temperature range, TSRS and CRS also have a crosstemperature range. An important practical engineering application issue arises here, that is, which system is more energy-efficient and economical to operate in the crosstemperature range?

There are few papers on the energetic and economic analysis of the three systems applied in different
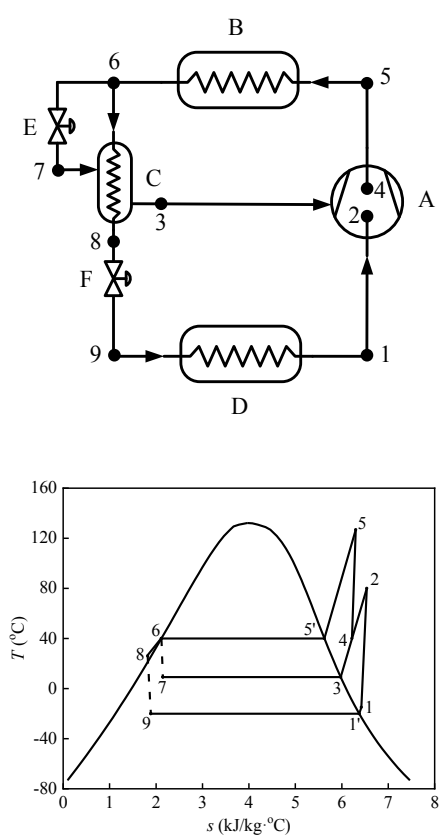

A: compressor, B: condenser,

$\mathrm{C}$ : economiser, D: evaporator,

E: throttle valve, F: throttle valve
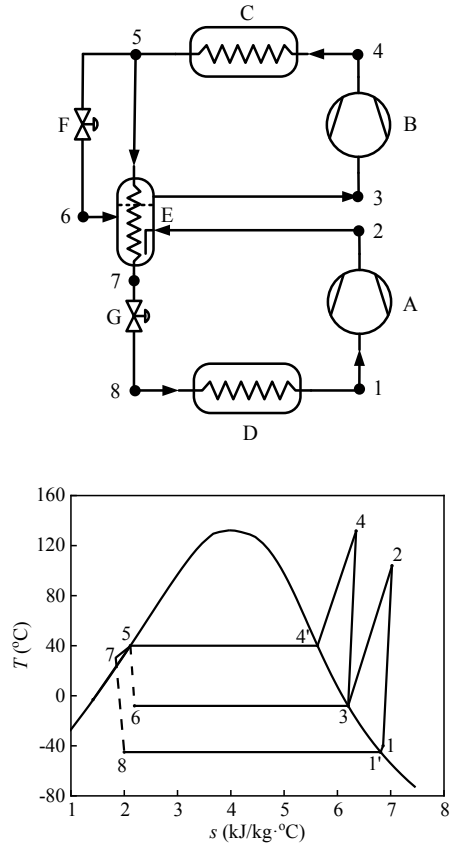

A: compressor of LTS,

B: compressor of HTS,

$\mathrm{C}$ : condenser, D: evaporator,

E: inter-stage cooler, F: throttle valve, G: throttle valve

Figure 2. Schematic and $T-s$ diagram of TSRS.
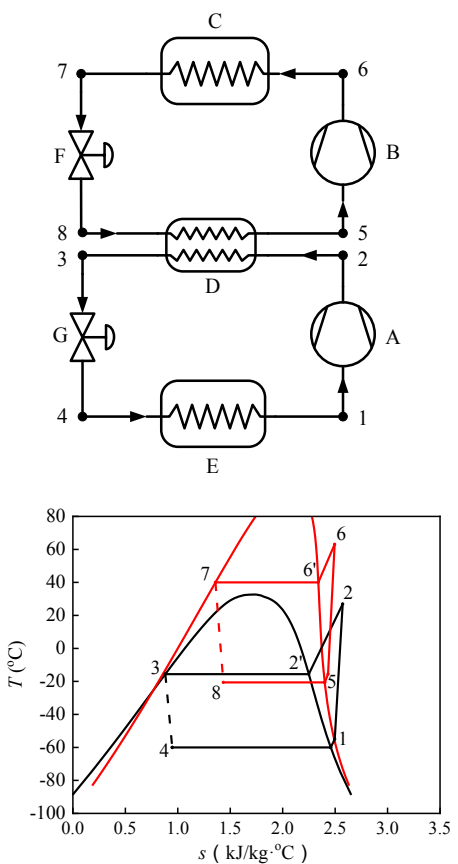

A: compressor of LTC, B: compressor of HTC, $\mathrm{C}$ : condenser, D: cascade heat exchanger, E: evaporator, F: throttle valve of HTC, G: throttle valve of LTC

Figure 3. Schematic and $T-s$ diagram of CRS.
Figure 1. Schematic and $T-s$ diagram of SSRS+E. 
temperature ranges, of which Wang et al. (2009) conducted experiments to compare SSRS+E, TSRS, and R744/ R717 CRS. The results show that when the evaporating temperature is lower than $-40^{\circ} \mathrm{C}$, the coefficient of performance (COP) of R744/R717 CRS is the highest. Messineo (2012) conducted a thermodynamic analysis of R744/R717 CRS and R404A TSRS, it found that R744/ R717 CRS could replace R404A TSRS in the evaporating temperature range of $-50^{\circ} \mathrm{C}$ to $-30^{\circ} \mathrm{C}$. In the evaporating temperature range of $-50^{\circ} \mathrm{C}$ to $-20^{\circ} \mathrm{C}$, Llopis et al. (2015) presented simplified models of five different TSRSs and CRSs, and analysed and compared their energy performance and environmental characteristics. The results show that for centralised commercial refrigeration at low temperature, the most promising candidates are the cascades with $\mathrm{CO}_{2}$ as low temperature fluid. Luyben (2019) conducted an energetic and economic study on refrigerant selection for different cryogenic temperatures. The main conclusion of this study is that the required refrigeration temperature has a strong impact on the economic aspects, the process configuration (number of stages), the selection of the refrigerant in each stage, and the temperatures in the intermediate stages.

However, the above research has deficiencies in three aspects: refrigeration temperature ranges, the integrity of research methods, and the selection of refrigerants. To address this issue, a deep research needs to be conducted. Therefore, in order to determine which form of vapour compression refrigeration systems are suitable for application in different temperature ranges to maximise the energetic and economic efficiency, this study employed natural refrigerants R717, R744 and R170 in the evaporating temperature range of $-75^{\circ} \mathrm{C}-0^{\circ} \mathrm{C}$, established thermodynamic models of SSRS $+\mathrm{E}$, TSRS and CRS, and combined the actual operation data of refrigeration units for analysis. The research results could provide reference for engineers to design refrigeration units in different temperature ranges.

\section{Research methods and processes}

\subsection{Description of three refrigeration systems}

The schematic diagram of the three refrigeration systems and their corresponding temperature-entropy diagram are shown in Figures 1 - 3 respectively. As shown in Figure 1, firstly, the refrigerant arrives at state 1 by a constant pressure gasification endothermic process in the evaporator (D). Entering the compressor (A), the refrigerant vapour is compressed to state 2 in the adiabatic condition. The refrigerant is mixed with the refrigerant of state 3 from the economiser outlet to state 4 . The mixed refrigerant then is compressed again to state 5 in the adiabatic condition. Entering the condenser (B), the refrigerant arrives at state 6 by the process of condensation under constant pressure.
Then the liquid from the condenser (B) is divided into two paths: the liquid of the first path enters the economiser (C) coil and is subcooled by the evaporation of liquid outside the coil to state 8 , and the refrigerant passes through an adiabatic throttling process to state 9 . The refrigerant then re-enters the evaporator (D) to absorb heat. The liquid of the second path enters the throttle valve (E) and passes through an adiabatic throttling process to state 7. Entering the economiser $(\mathrm{C})$, the throttled liquid evaporates in the economiser (C) to subcool the high-pressure liquid in the coil to state 3 .

Finally, the refrigerant enters the compressor through the way of intermediate gas-injection to complete the whole cycle.

The cycle process of TSRS and CRS are similar to that of SSRS+E. The difference is that the economiser is replaced by an inter-stage cooler in TSRS as shown in Figure 2. High-temperature cycle (HTC) and lowtemperature cycle (LTC) of CRS are combined with the cascade heat exchanger (CHX) (D) to form a CRS. The evaporation process of HTC and the condensation process of LTC complete the heat transfer in CHX (D) as shown in Figure 3.

\subsection{Mathematical models of thermodynamic analysis}

MATLAB was used to extract the data in REFPROP 9.0 (Lemmon et al., 2013) for simulation analysis in this study. To simplify the calculation of the models, the analysis was conducted based on the following assumptions:

(1) The superheating occurring in the evaporator and $\mathrm{CHX}$ is effective and is set as $5^{\circ} \mathrm{C}$, and the refrigerant is at the saturated state at the condenser outlet.

(2) The pressure drops and heat losses of fluid flowing inside the heat exchangers and connecting pipes are ignored.

(3) The system runs under a steady working condition.

(4) The compression process is adiabatic but nonisentropic (as shown in Figures 1 - 3), and the isentropic efficiency is set as $80 \%$, and the expansion processes are adiabatic.

(5) The temperature difference in $\mathrm{CHX}$ is set as $5^{\circ} \mathrm{C}$ and the effectiveness of the heat exchanger (Klein et al., 2000 ) is set as $60 \%$.

(6) The cooling capacity $\left(Q_{e}\right)$ is set as $10 \mathrm{~kW}$ and the condensing temperature is set as $40^{\circ} \mathrm{C}$.

The other instructions about this study are as follows:

(1) In theory, there is a temperature difference at the end of the inter-stage cooler, and the temperature of state 7 as shown in Figure $2\left(t_{7}\right)$ is $5^{\circ} \mathrm{C}$ higher than the middle temperature $\left(t_{m}\right)$, as shown in the following formula: $t_{7}-t_{m}=5^{\circ} \mathrm{C}$. However, during the actual design process of the inter-stage cooler, the high-pressure 
refrigerant liquid is set to be subcooled by $5^{\circ} \mathrm{C}$ after passing through the inter-stage cooler coil, as shown in the following formula: $t_{5}-t_{7}=5^{\circ} \mathrm{C}$. Therefore, this study adopts the second calculation formula to simulate TSRS.

(2) The inter-stage pressure must be determined during the simulation of SSRS+E, TSRS, and CRS (Purohit et al., 2016). Based on the principle of maximum system COP, MATLAB programming was used to calculate the corresponding optimal inter-stage pressure by iteration of each evaporating temperature in the process of system circulation. The rest of the system parameters are calculated based on the optimal inter-stage pressure.

The enthalpy, specific volume, and pressure, etc of refrigerants were calculated by programming according to the refrigeration cycle characteristics. Based on each cycle state point of SSRS+E, TSRS, and CRS (as shown in Figures 1 - 3), the corresponding mathematical models were established respectively, as shown in Table 1.

Based on different refrigeration needs, the refrigeration temperature range was divided into two parts (Luyben, 2019): $-30^{\circ} \mathrm{C}$ to $0^{\circ} \mathrm{C}$ and $-75^{\circ} \mathrm{C}$ to $-30^{\circ} \mathrm{C}$. This study conducted an energetic and economic analysis of SSRS+E and TSRS in the evaporating temperature range of $-30^{\circ} \mathrm{C}$ to $0^{\circ} \mathrm{C}$ as well as an energetic and economic analysis of TSRS and $\mathrm{CRS}$ in the evaporating temperature range of $-75^{\circ} \mathrm{C}$ to $-30^{\circ} \mathrm{C}$. The SSRS+E and TSRS selected the refrigerant R717 while CRS selected the refrigerant couples R170/ R717 and R744/R717.

\section{Results and discussion}

\subsection{Theoretical analysis of SSRS $+E$ and TSRS}

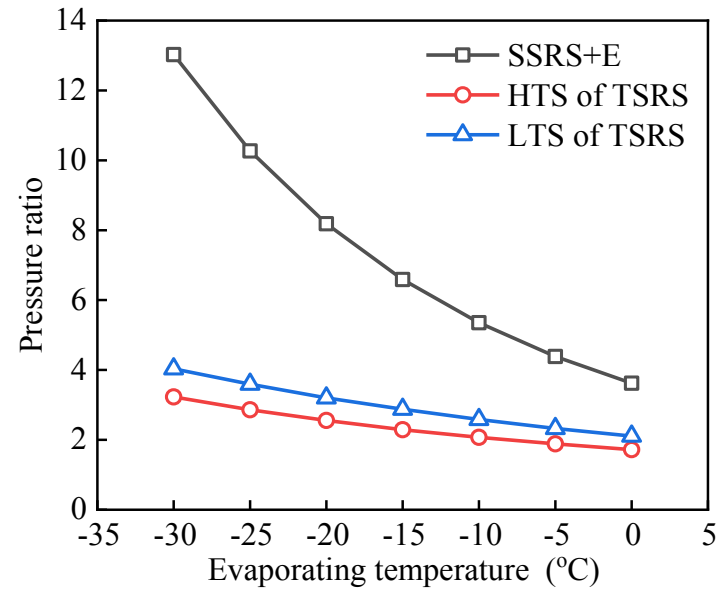

Figure 4. The pressure ratio varies with the evaporating temperature.
Table 1. The mathematical models of three refrigeration systems.

\begin{tabular}{|c|c|c|}
\hline System & Component/Parameters & $\begin{array}{l}\text { Energy balance equations/ } \\
\text { Formulations }\end{array}$ \\
\hline \multirow{6}{*}{$\mathrm{SSRS}+\mathrm{E}$} & Evaporator & $m_{e}=\frac{Q_{e}}{h_{1}-h_{9}}$ \\
\hline & Economiser & $m_{E c o}=m_{e}\left(\frac{h_{6}-h_{8}}{h_{3}-h_{7}}\right)$ \\
\hline & Compressor & $\begin{array}{c}W=m_{e}\left(h_{2}-h_{1}\right)+\left(m_{E c o}+m_{e}\right)\left(h_{5}-h_{4}\right) \\
m \times v\end{array}$ \\
\hline & $q_{v h}$ & $q_{v h}=\frac{m_{e} \times v_{1}}{\eta_{v}}$ \\
\hline & $\varepsilon$ & $\varepsilon=\frac{p_{5}}{p_{1}}$ \\
\hline & COP & $C O P=\frac{Q_{e}}{W}$ \\
\hline \multirow{9}{*}{ TSRS } & Evaporator & $m_{l}=\frac{Q_{e}}{h_{1}-h_{8}}$ \\
\hline & Compressor of LTS & $W_{l}=m_{l}\left(h_{2}-h_{1}\right)$ \\
\hline & $q_{v h}$ of LTS & $q_{v h, l}=\frac{m_{l} \times v_{1}}{\eta_{v}}$ \\
\hline & $\varepsilon$ of LTS & $\varepsilon_{l}=\frac{p_{2}}{p_{1}}$ \\
\hline & $m_{h}$ & $m_{h}=m_{l}\left(\frac{h_{2}-h_{7}}{h_{3}-h_{6}}\right)$ \\
\hline & Compressor of HTS & $W_{h}=m_{h}\left(h_{4}-h_{3}\right)$ \\
\hline & $q_{v h}$ of HTS & $q_{v h, h}=\frac{m_{h} \times v_{3}}{\eta_{v}}$ \\
\hline & $\varepsilon$ of HTS & $\varepsilon_{h}=\frac{p_{4}}{p_{3}}$ \\
\hline & $\mathrm{COP}$ & $C O P=\frac{Q_{e}}{W_{l}+W_{\mathrm{h}}}$ \\
\hline \multirow{11}{*}{ CRS } & Evaporator & $m_{l}=\frac{Q_{e}}{h_{1}-h_{4}}$ \\
\hline & Compressor of LTC & $W_{l}=m_{l}\left(h_{2}-h_{1}\right)$ \\
\hline & $q_{v h}$ of LTC & $q_{v h, l}=\frac{m_{l} \times v_{1}}{\eta_{v}}$ \\
\hline & $\varepsilon$ of LTC & $\varepsilon_{l}=\frac{p_{2}}{p_{1}}$ \\
\hline & $\mathrm{CHX}$ & $Q_{C H X}=m_{l}\left(h_{2}-h_{3}\right)=m_{h}\left(h_{5}-h_{8}\right)$ \\
\hline & $m_{h}$ & $m_{h}=m_{l}\left(\frac{h_{2}-h_{3}}{h_{5}-h_{8}}\right)$ \\
\hline & Compressor of HTC & $W_{h}=m_{h}\left(h_{6}-h_{5}\right)$ \\
\hline & $q_{v h}$ of HTC & $q_{v h, h}=\frac{m_{h} \times v_{5}}{\eta_{v}}$ \\
\hline & $\varepsilon$ of HTC & $\varepsilon_{h}=\frac{p_{6}}{p_{5}}$ \\
\hline & COP & $C O P=\frac{Q_{e}}{W_{l}+W_{h}}$ \\
\hline & Volumetric efficiency $\eta_{v}$ & $\begin{array}{l}\eta_{v}=a \varepsilon^{\frac{1}{k}-1}+\left(b+c \varepsilon^{-1}\right) \varepsilon^{\frac{1}{2 k}} \sqrt{2 v_{1}\left(p_{2}-p_{1}\right)} \\
\text { Where, } v_{l} \text { is the suction specific } \\
\text { volume, } p_{1} \text { and } p_{2} \text { are the suction } \\
\text { pressure and the discharging } \\
\text { pressure respectively. } a, b \text {, and } \\
c \text { can be obtained through an } \\
\text { experiment (Liu et al., 2012) and } \\
\text { they are } 0.787773,0.000052881, \\
\text { and } 0.0024345, \text { respectively. } k \text { is } \\
\text { the polytropic exponent. }\end{array}$ \\
\hline
\end{tabular}




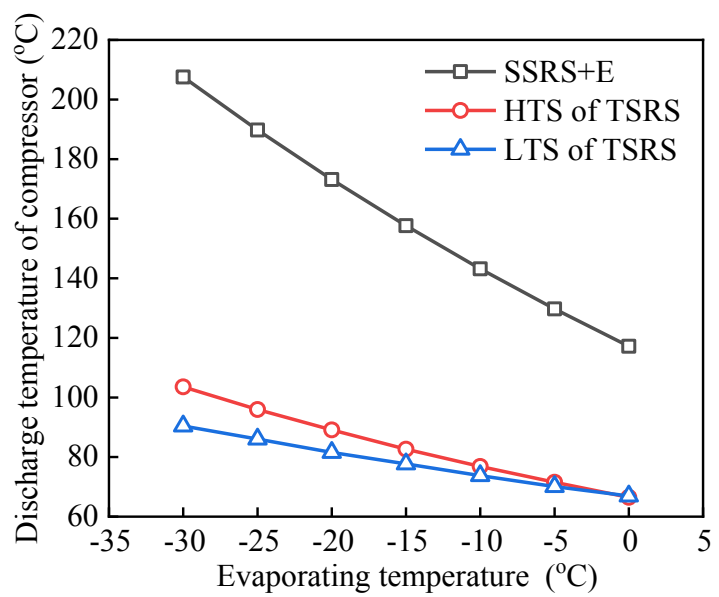

Figure 5. The discharge temperature of compressor varies with the evaporating temperature.

Figures 4 and 5 illustrate the variation trend of the pressure ratio and the discharge temperature of compressor under different evaporating temperatures. Figure 4 shows that the pressure ratio decreases with the increase in the evaporating temperature. At a fixed condensing temperature $\left(40^{\circ} \mathrm{C}\right)$, as the evaporating temperature increases, the inlet pressure of compressor increases while the discharge pressure does not change, which results in a decrease in the pressure ratio. In the comparison of the two systems, the pressure ratio of SSRS+E is the highest and that of HTS of TSRS and LTS of TSRS are relatively lower and closer, and their pressure ratios are around $3-4$. The use of two compressors in TSRS shares the pressure ratio together so that the pressure ratio of each compressor is in an appropriate range.

In addition, compared with SSRS+E, the pressure ratio of TSRS could be reduced at maximum by $52.6 \%$ $75.2 \%$ in the evaporating temperature range of $-30^{\circ} \mathrm{C}-0^{\circ} \mathrm{C}$. Due to the high adiabatic index, it is recommended that the pressure ratio of the R717 system should not be too high. Under this condition, the lowest evaporating temperature that $\mathrm{R} 717 \mathrm{SSRS}+\mathrm{E}$ can reach is $-20^{\circ} \mathrm{C}$. From the pressure ratio point of view, $\mathrm{R} 717$ TSRS is more advantageous when the evaporating temperature is below $-20^{\circ} \mathrm{C}$.

As shown in Figure 5, the discharge temperature of compressor decreases with the increasing evaporating temperature. The reason is shown in Figure 4, where the pressure ratio decreases with the increase in evaporating temperature, while the inlet temperature of compressor increases with the increase in evaporating temperature. At a fixed condensing temperature, the degree of the pressure ratio reduction is greater than that of the increase of the inlet temperature of compressor, so the discharge temperature of compressor is reduced. From this phenomenon, we can conclude that the pressure ratio is a key factor affecting the discharge temperature of compressor. In the comparison of the two systems, the discharge temperature of compressor of SSRS+E is the highest with greatest fluctuation. The discharge temperatures of compressor of HTS of TSRS and LTS of TSRS are the lowest and relatively stable, and they are all lower than the maximum discharge temperature specified by the R717 system.

In addition, the compressor discharge temperature of SSRS+E is higher than that of LTS of TSRS by $50.3^{\circ} \mathrm{C}-$ $117.1^{\circ} \mathrm{C}$ in the evaporating temperature range of $-30^{\circ} \mathrm{C}-$ $0^{\circ} \mathrm{C}$. The lower the discharge temperature, the lower the possibility of the compressor oil to carbonise, ensuring better performance of the compressor lubrication for a long time and enhancing the reliability of the system. From the discharge temperature of compressor point of view, R717 TSRS is more advantageous when the evaporating temperature is lower.

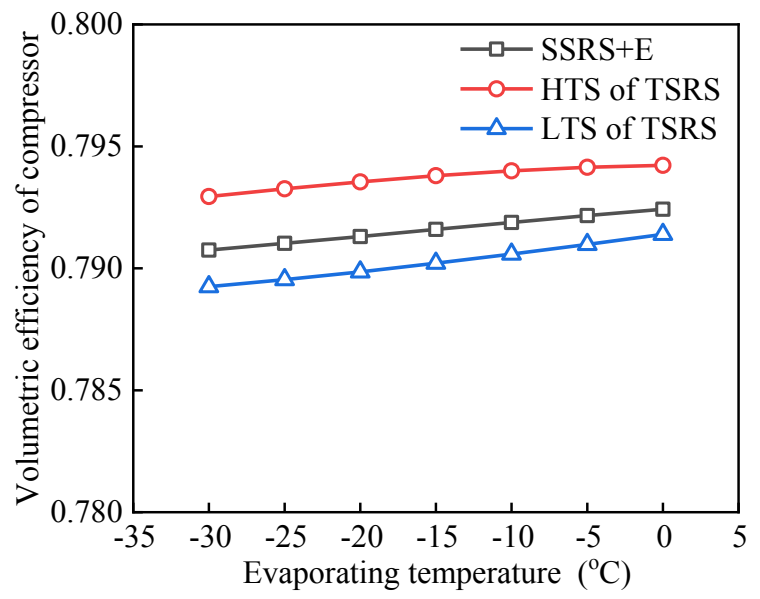

Figure 6. The volumetric efficiency of compressor varies with the evaporating temperature.

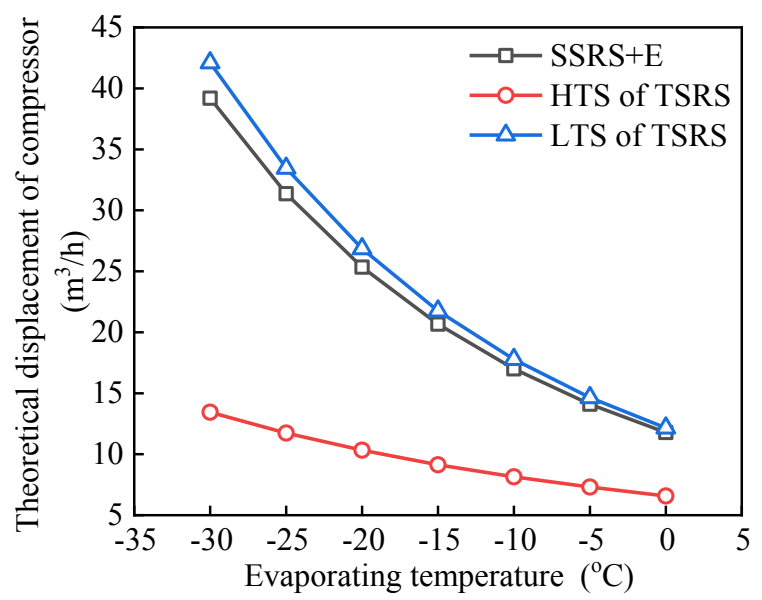

Figure 7. The theoretical displacement of compressor varies with the evaporating temperature.

Figures 6 and 7 illustrate the variation trend in the volumetric efficiency of compressor and the theoretical displacement of compressor under different evaporating 
temperatures. The volumetric efficiency of compressor increases with the increase in evaporating temperature, while the theoretical displacement of compressor decreases with the increase in the evaporating temperature. The reason is shown in Figure 4, where the pressure ratio decreases with the increase in the evaporating temperature, which results in an increase in the volumetric efficiency of compressor and a decrease in the theoretical displacement of compressor. In the comparison of the two systems, the volumetric efficiency of compressor of LTS of TSRS is the lowest, while HTS of TSRS is the highest. The compressor theoretical displacement of LTS of TSRS and SSRS+E are much higher than that of HTS of TSRS, so the size of compressor of these are relatively large, requiring greater operation space and higher costs.

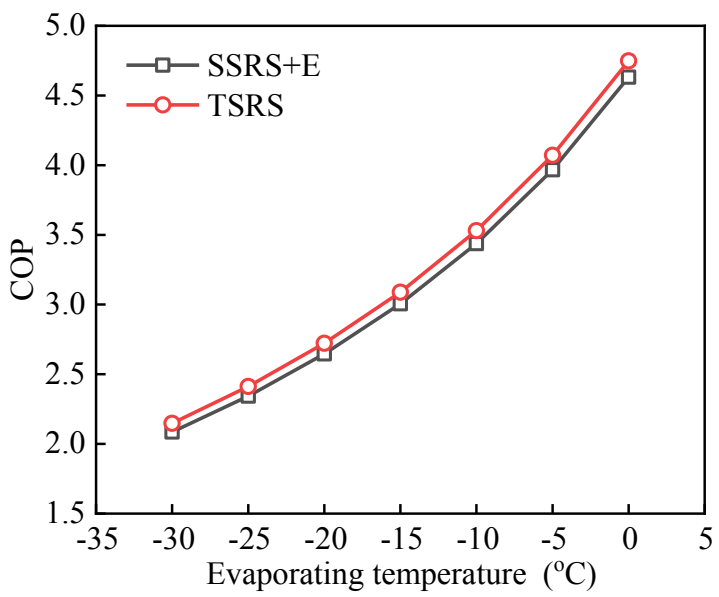

Figure 8. COP varies with the evaporating temperature.

As shown in Figure 8, the system COP increases with the increase in evaporating temperature. In the comparison of the two systems, the system COP of R717 TSRS is the highest and higher than that of SSRS+E by $2.5 \%-3.0 \%$ in the evaporating temperature range of $-30^{\circ} \mathrm{C}-0^{\circ} \mathrm{C}$. In theory, the R717 TSRS energy efficiency is higher than that of $\mathrm{SSRS}+\mathrm{E}$, which is more advantageous in the refrigeration temperature range of $-30^{\circ} \mathrm{C}-0^{\circ} \mathrm{C}$. This is because the use of inter-stage cooler in TSRS results in lower compressor inlet temperature of HTS, which makes lower the compressor specific input power of HTS. Besides, at the fixed cooling capacity $(10 \mathrm{~kW})$, the increasing subcooling degree of the refrigerant decreases the mass flow rate of refrigerant in the system, and results in a decrease in the total input power of the compressor in TSRS. So, for the same cooling capacity, the COP of TSRS is theoretically higher than that of SSRS+E.

\subsection{Economic analysis of SSRS $+E$ and TSRS}

Taking the actual refrigeration units of freezing and cold storage as the research object, this study conducted an economic analysis of the initial investment and operating costs of the two systems in the operating conditions where the evaporating temperatures are $-15^{\circ} \mathrm{C},-20^{\circ} \mathrm{C},-25^{\circ} \mathrm{C}$, and $-30^{\circ} \mathrm{C}$, respectively. The actual refrigeration unit configuration scheme is shown in Table 2.

A calculation of compressor energy consumption for the two systems was carried out. Due to the different operating requirements for freezing and cold storage refrigeration systems, the running times of compressor are also different throughout the year. This study assumes a compressor working for 100 days, 200 days, and 300 days throughout the year, with a daily operation time of 15 hours and a unit price of electricity at $0.8 \mathrm{RMB} / \mathrm{kWh}$. The annual energy consumption of the two systems under different operation hours are shown in Table 3.

Tables 2 and 3 show that SSRS+E consumed more energy than TSRS, that is, the system COP of SSRS+E is lower than TSRS only when the evaporating temperature is $-30^{\circ} \mathrm{C}$. However, when the evaporating temperature was higher than $-25^{\circ} \mathrm{C}, \mathrm{SSRS}+\mathrm{E}$ is more energy-efficient than TSRS, which means the system COP of SSRS+E is larger than that of TSRS. That is different from the previous theoretical analysis as shown in Figure 8.

On the one hand, in theoretical analysis, the use of inter-stage cooler in TSRS greatly increases the subcooling degree of refrigerant and indirectly increases the cooling capacity. Besides, the compressor inlet temperature of HTS is dropped, which reduces the compressor input power. Therefore, at the same condensing and evaporating temperatures, the COP of TSRS is higher than SSRS+E.

On the other hand, in economic analysis, all the refrigeration equipment selected for the study is real objects rather than computer programs, and the operation data are accurately measured. When the evaporating temperature is higher than $-25^{\circ} \mathrm{C}$, the COP of the actual TSRS is smaller than that of the theoretical analysis because, firstly, the efficiency of the inter-stage cooler of the actual TSRS is too low to reach such a large subcooling degree of refrigerant in the theoretical analysis, and secondly, based on the principle of maximum system COP, there is an optimal inter-stage pressure during the simulation of TSRS (Purohit et al., 2016). The actual TSRS does not operate under optimal inter-stage pressure.

In view of this situation where contradictions arise between theoretical analysis results and actual operation data, some conclusions of this part are more based on economic analysis rather than theoretical analysis, because those economic analyses are based on real operation data and have more practical significance for application. Besides, the results of the theoretical analysis also give direction to improve the actual performance of TSRS. This contradiction is of great research value.

In economic analysis, when the evaporating temperature was above $-25^{\circ} \mathrm{C}, \mathrm{SSRS}+\mathrm{E}$ was superior to TSRS in energy consumption. In addition, compared with TSRS, SSRS+E could save energy by $20.6 \%, 13.6 \%$ and $7.1 \%$, with maximum annual electricity cost savings of 2,988.0 RMB, 2,124.0 RMB and 1,188.0 RMB, in the 
evaporating temperatures of $-15^{\circ} \mathrm{C},-20^{\circ} \mathrm{C}$, and $-25^{\circ} \mathrm{C}$, respectively.

As shown in Table 2, the refrigeration unit investment costs of TSRS were less than those of SSRS+E by 40.7 $\mathrm{RMB}, 780.8 \mathrm{RMB}$ and $1,722.8 \mathrm{RMB}$, in the evaporating temperatures of $-15^{\circ} \mathrm{C},-20^{\circ} \mathrm{C}$ and $-25^{\circ} \mathrm{C}$, respectively. However, for SSRS+E, with its excellent energy-saving performance, the difference in refrigeration unit investment costs between SSRS+E and TSRS can be recovered for up to one year, in the evaporating temperatures of $-15^{\circ} \mathrm{C}$ and $-20^{\circ} \mathrm{C}$. For the evaporating temperature of $-25^{\circ} \mathrm{C}$, the payback period of SSRS+E is between 1.5 and 4 years. This is an acceptable range, especially when SSRS+E runs longer to use. Besides, considering the higher cost of equipment maintenance due to the complexity of TSRS, the payback period of SSRS+E will be further shortened. Based on the above discussion, SSRS+E is recommended for use above the evaporating temperature of $-25^{\circ} \mathrm{C}$. TSRS is recommended for use below the evaporating temperature of $-25^{\circ} \mathrm{C}$.

\subsection{Theoretical analysis of TSRS and CRS}

Figures 9 and 10 show that the pressure ratio decreases with the increase in the evaporating temperature, and the discharge temperature of compressor decreases with the increasing evaporating temperature. The refrigeration cycle using R717 as refrigerant has a larger pressure ratio and a higher compressor discharge temperature. In addition, the pressure ratio of HTC of CRS is greater than that of HTS of TSRS, while the compressor discharge temperature of HTC of CRS is higher than that of TSRS. The pressure ratio of LTC of CRS is the smallest, and the compressor discharge temperature of CRS is the lowest, which is related to the choice of low-temperature refrigerant. Compared with HTC of CRS, the pressure ratio of TSRS can be reduced by a maximum of $8.9 \%-43.2 \%$ and the compressor discharge temperature of that can be reduced by a maximum of $7.0^{\circ} \mathrm{C}$ $-45.5^{\circ} \mathrm{C}$ in the evaporating temperature range of $-75^{\circ} \mathrm{C}$ to $-30^{\circ} \mathrm{C}$.

Table 2. Refrigeration unit configuration scheme of SSRS+E and TSRS.

\begin{tabular}{|c|c|c|c|c|c|c|c|c|}
\hline System & \multicolumn{4}{|c|}{ SSRS+E } & \multicolumn{4}{|c|}{ TSRS } \\
\hline Compressor model & \multicolumn{4}{|c|}{ LG12M(R717) } & \multicolumn{4}{|c|}{ LG1612MMZ(Y)(R717) } \\
\hline Number of units & \multicolumn{4}{|c|}{1} & \multicolumn{4}{|c|}{1} \\
\hline Cooling capacity $[\mathrm{kW}]$ & \multicolumn{4}{|c|}{10} & \multicolumn{4}{|c|}{10} \\
\hline$T_{e}\left[{ }^{\circ} \mathrm{C}\right]$ & -15 & -20 & -25 & -30 & -15 & -20 & -25 & -30 \\
\hline Shaft power [kW] & 3.20 & 3.74 & 4.35 & 5.17 & 4.03 & 4.33 & 4.68 & 5.12 \\
\hline Quoted price [RMB] & $19,186.9$ & $23,683.6$ & $29,538.5$ & $37,435.2$ & $19,146.2$ & $22,902.8$ & $27,815.7$ & $34,345.0$ \\
\hline
\end{tabular}

Table 3. Annual energy consumption of SSRS+E and TSRS.

\begin{tabular}{|c|c|c|c|c|c|}
\hline$T_{e}\left[{ }^{\circ} \mathrm{C}\right]$ & Operation hours $[\mathrm{h}]$ & System & $\begin{array}{c}\text { Power consumption } \\
\text { per hour }[\mathrm{kW}]\end{array}$ & $\begin{array}{c}\text { Cost savings [RMB] } \\
\text { (SSRS+E relative to TSRS) }\end{array}$ & $\begin{array}{c}\text { Saving percentage [\%] } \\
\text { (SSRS+E relative to TSRS) }\end{array}$ \\
\hline \multirow{6}{*}{-15} & \multirow{2}{*}{1,500} & $\mathrm{SSRS}+\mathrm{E}$ & 3.20 & \multirow{2}{*}{996.0} & \multirow{6}{*}{20.6} \\
\hline & & TSRS & 4.03 & & \\
\hline & \multirow{2}{*}{3,000} & $\mathrm{SSRS}+\mathrm{E}$ & 3.20 & \multirow{2}{*}{$1,992.0$} & \\
\hline & & TSRS & 4.03 & & \\
\hline & \multirow{2}{*}{4,500} & $\mathrm{SSRS}+\mathrm{E}$ & 3.20 & \multirow{2}{*}{$2,988.0$} & \\
\hline & & TSRS & 4.03 & & \\
\hline \multirow{6}{*}{-20} & \multirow{2}{*}{1,500} & $\mathrm{SSRS}+\mathrm{E}$ & 3.74 & \multirow{2}{*}{708.0} & \multirow{6}{*}{13.6} \\
\hline & & TSRS & 4.33 & & \\
\hline & \multirow{2}{*}{3,000} & $\mathrm{SSRS}+\mathrm{E}$ & 3.74 & \multirow{2}{*}{$1,416.0$} & \\
\hline & & TSRS & 4.33 & & \\
\hline & 500 & $\mathrm{SSRS}+\mathrm{E}$ & 3.74 & \multirow{2}{*}{$2,124.0$} & \\
\hline & 4,500 & TSRS & 4.33 & & \\
\hline \multirow{6}{*}{-25} & \multirow{2}{*}{1,500} & $\mathrm{SSRS}+\mathrm{E}$ & 4.35 & \multirow{2}{*}{396.0} & \multirow{6}{*}{7.1} \\
\hline & & TSRS & 4.68 & & \\
\hline & \multirow{2}{*}{3,000} & $\mathrm{SSRS}+\mathrm{E}$ & 4.35 & \multirow{2}{*}{792.0} & \\
\hline & & TSRS & 4.68 & & \\
\hline & 4500 & $\mathrm{SSRS}+\mathrm{E}$ & 4.35 & \multirow{2}{*}{$1,188.0$} & \\
\hline & 4,500 & TSRS & 4.68 & & \\
\hline \multirow{6}{*}{-30} & \multirow{2}{*}{1,500} & $\mathrm{SSRS}+\mathrm{E}$ & 5.17 & \multirow{2}{*}{-60.0} & \multirow{6}{*}{-0.97} \\
\hline & & TSRS & 5.12 & & \\
\hline & 3.000 & $\mathrm{SSRS}+\mathrm{E}$ & 5.17 & -1200 & \\
\hline & J, & TSRS & 5.12 & -120.0 & \\
\hline & \multirow{2}{*}{4,500} & SSRS+E & 5.17 & \multirow{2}{*}{-180.0} & \\
\hline & & TSRS & 5.12 & & \\
\hline
\end{tabular}




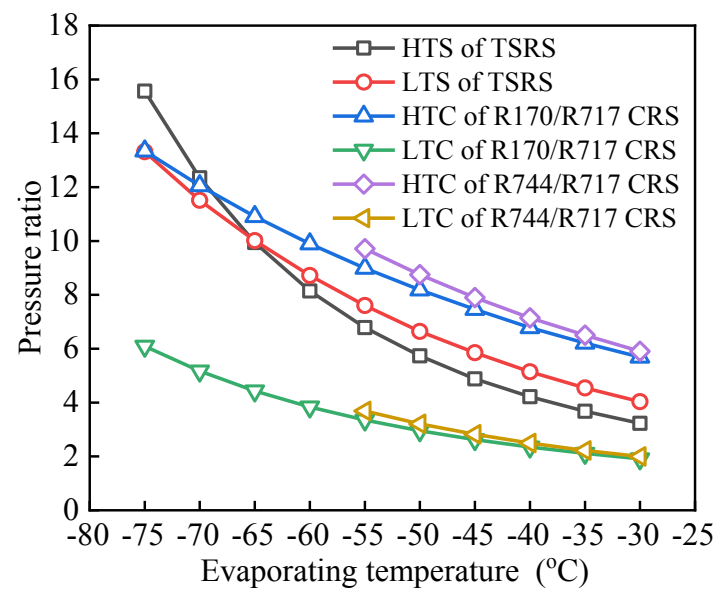

Figure 9. The pressure ratio varies with the evaporating temperature.

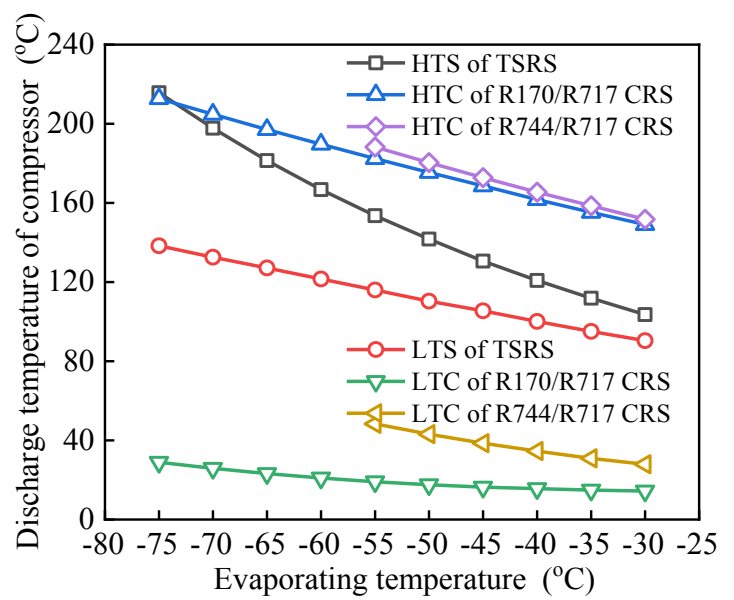

Figure 10. The discharge temperature of compressor varies with the evaporating temperature.

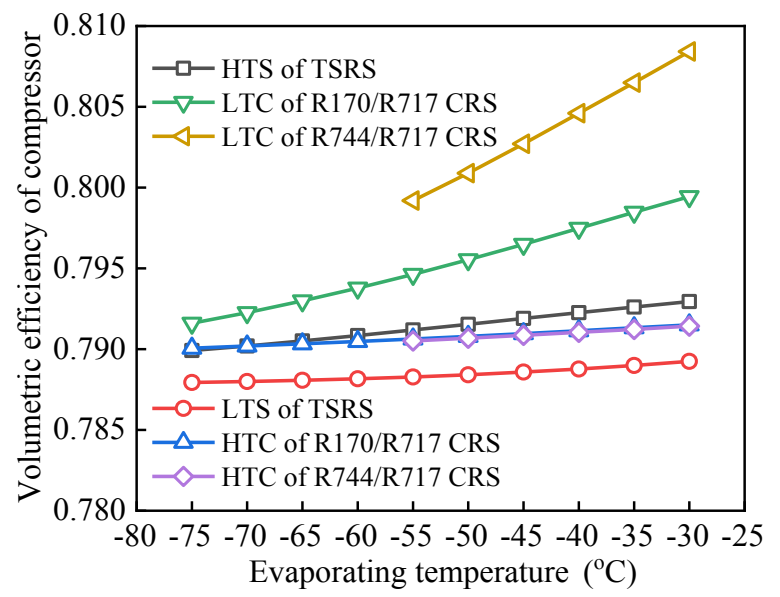

Figure 11. The volumetric efficiency of compressor varies with the evaporating temperature.

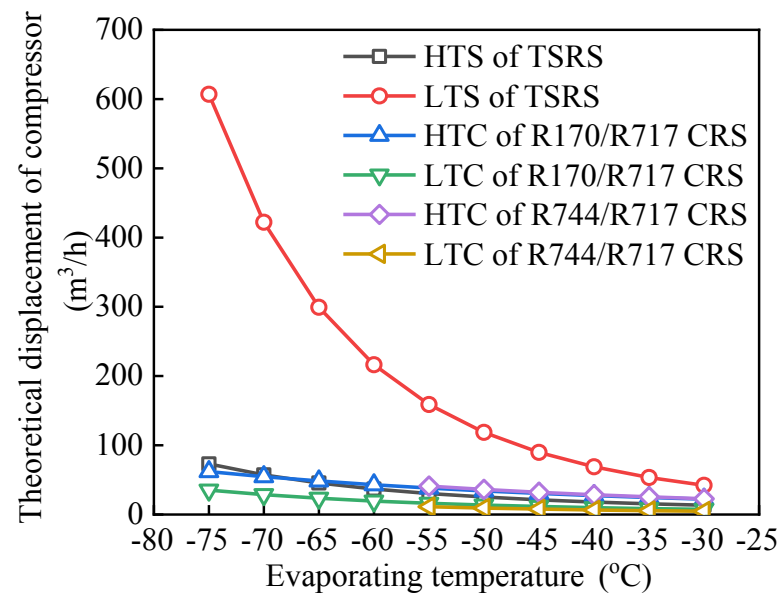

Figure 12. The theoretical displacement of compressor varies with the evaporating temperature.

Figures 11 and 12 illustrate that the volumetric efficiency of compressor increases with the increase in evaporating temperature, while the theoretical displacement of compressor decreases with the increase in evaporating temperature. Figure 11 shows that the volumetric efficiency of HTS of TSRS and LTS of TSRS are relatively lower than that of R170/R717 CRS and R744/R717 CRS. Figure 12 shows that the compressor theoretical displacement of LTS of TSRS is much higher than that of CRS when the evaporating temperature is lower. Therefore, the size of compressor it used is relatively large, requiring greater operation space and higher costs. Compared with other cycles, the compressor theoretical displacement of LTS of TSRS is greatly affected by the decrease in evaporating temperature. The compressor theoretical displacements of TSRS, R170/R717 CRS, and R744/R717 CRS are $0.19 \mathrm{~m}^{3} / \mathrm{h}$, $2.35 \mathrm{~m}^{3} / \mathrm{h}$, and $3.61 \mathrm{~m}^{3} / \mathrm{h}$, respectively, in the evaporating temperature of $-55^{\circ} \mathrm{C}$. From the compressor operation point of view, CRS is more advantageous when the evaporating temperature is lower.

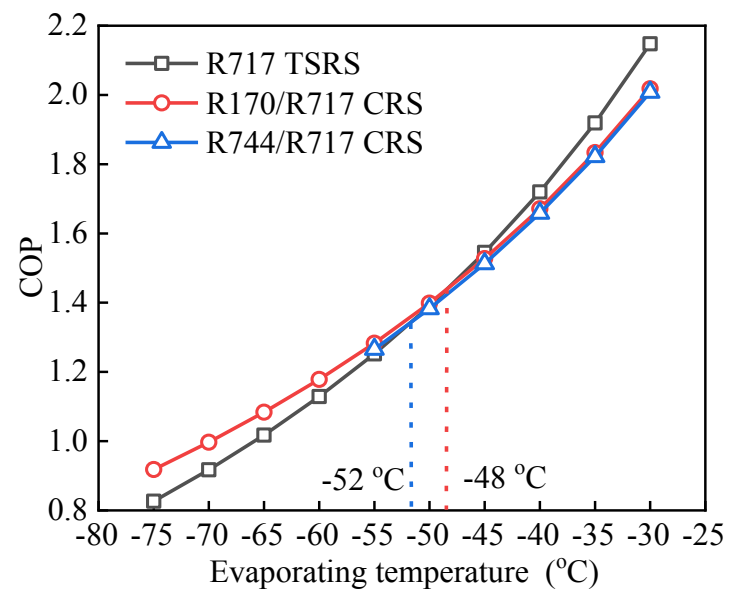

Figure 13. COP varies with the evaporating temperature. 
Figure 13 illustrates that the system COP increases with the increasing evaporating temperature. There is a cross-point of the COP curves between TSRS and CRS. Under the assumptions defined in this study, the corresponding evaporating temperatures at the cross-point of TSRS with R170/R717 CRS and R744/R717 CRS are $-48^{\circ} \mathrm{C}$ and $-52^{\circ} \mathrm{C}$, respectively. In addition, when the evaporating temperature is below $-48^{\circ} \mathrm{C}$, the COP of R170/ R717 CRS is higher than that of TSRS. For example, compared with TSRS, the COP of R170/R717 CRS is increased by $8.7 \%$ in the evaporating temperature of $-70^{\circ} \mathrm{C}$. Conversely, when the evaporating temperature is above $-48^{\circ} \mathrm{C}$, the COP of TSRS is higher than that of R170/R717 CRS. For example, compared with R170/R717 CRS, the COP of TSRS is increased by $2.9 \%$ in the evaporating temperature of $-40^{\circ} \mathrm{C}$. Therefore, the energy efficiency of CRS is much higher, which is more advantageous when the evaporating temperature is lower.

\subsection{Economic analysis of TSRS and CRS}

Same as the discussion of the above economic analysis of SSRS+E and TSRS, the refrigeration unit configuration scheme and the annual energy consumption of TSRS and
CRS under different operating times are shown in Tables 4 and 5 .

Tables 4 and 5 show that when the evaporating temperature is below $-45^{\circ} \mathrm{C}, \mathrm{R} 744 / \mathrm{R} 717 \mathrm{CRS}$ is superior to TSRS in energy consumption and refrigeration unit investment costs. However, Figure 13 in theoretical analysis shows that the COP of R744/R717 CRS is higher than that of TSRS only when the evaporating temperature is below $-52^{\circ} \mathrm{C}$. For evaporating temperature above $-52^{\circ} \mathrm{C}$, the result is the opposite. As mentioned before, the COP of TSRS is higher in theory due to the influence of more efficient inter-stage cooler. Obviously, this effect still exists in the low temperature range. This leads to the lower evaporating temperature corresponding to the cross-point of the COP curves between TSRS and CRS. Therefore, some conclusions of this part are also more based on economic analysis.

In addition, compared with TSRS, R744/R717 CRS can save energy by $14.1 \%, 18.8 \%$, and $27.9 \%$, with maximum annual electricity cost savings of 3,852.0 RMB, 6,228.0 RMB and 11,592.0 RMB, in the evaporating temperatures of $-45^{\circ} \mathrm{C},-50^{\circ} \mathrm{C}$ and $-55^{\circ} \mathrm{C}$, respectively. $\mathrm{R} 744 / \mathrm{R} 717 \mathrm{CRS}$, therefore, offers significant energetic and economic advantages, when the evaporating temperature

Table 4. Refrigeration unit configuration scheme of TSRS and CRS.

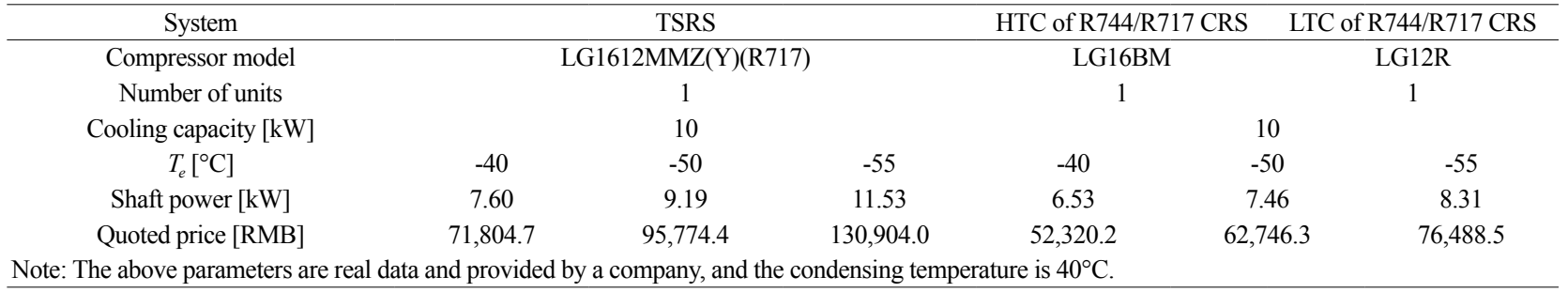

Table 5. Annual energy consumption of TSRS and CRS.

\begin{tabular}{|c|c|c|c|c|c|}
\hline$T_{e}\left[{ }^{\circ} \mathrm{C}\right]$ & Operation hours [h] & System & $\begin{array}{c}\text { Power consumption } \\
\text { per hour[kW] }\end{array}$ & $\begin{array}{c}\text { Cost savings [RMB] } \\
\text { (CRS relative to TSRS) }\end{array}$ & $\begin{array}{l}\text { Savings percentage }[\%] \\
\text { (CRS relative to TSRS) }\end{array}$ \\
\hline \multirow{6}{*}{-45} & \multirow{2}{*}{1500} & R744/R717 CRS & 6.53 & \multirow{2}{*}{$1,284.0$} & \multirow{6}{*}{14.1} \\
\hline & & TSRS & 7.60 & & \\
\hline & & R744/R717 CRS & 6.53 & \multirow{2}{*}{$2,568.0$} & \\
\hline & 3000 & TSRS & 7.60 & & \\
\hline & \multirow{2}{*}{4500} & R744/R717 CRS & 6.53 & \multirow{2}{*}{$3,852.0$} & \\
\hline & & TSRS & 7.60 & & \\
\hline \multirow{6}{*}{-50} & \multirow{2}{*}{1500} & R744/R717 CRS & 7.46 & \multirow{2}{*}{$2,076.0$} & \multirow{6}{*}{18.8} \\
\hline & & TSRS & 9.19 & & \\
\hline & 3000 & R744/R717 CRS & 7.46 & \multirow{2}{*}{$4,152.0$} & \\
\hline & 3000 & TSRS & 9.19 & & \\
\hline & 4500 & R744/R717 CRS & 7.46 & \multirow{2}{*}{$6,228.0$} & \\
\hline & 4500 & TSRS & 9.19 & & \\
\hline \multirow{6}{*}{-55} & \multirow{2}{*}{1500} & R744/R717 CRS & 8.31 & \multirow{2}{*}{$3,864.0$} & \multirow{6}{*}{27.9} \\
\hline & & TSRS & 11.53 & & \\
\hline & 3000 & R744/R717 CRS & 8.31 & \multirow{2}{*}{$7,728.0$} & \\
\hline & 5000 & TSRS & 11.53 & & \\
\hline & \multirow{2}{*}{4500} & R744/R717 CRS & 8.31 & \multirow{2}{*}{$11,592.0$} & \\
\hline & & TSRS & 11.53 & & \\
\hline
\end{tabular}


is below $-45^{\circ} \mathrm{C}$. Although the structure and operation of R744/R717 CRS are more complicated than other systems, considering its energetic and economic advantages, it is recommended for use below the evaporating temperature of $-45^{\circ} \mathrm{C}$, and TSRS is recommended for use in the evaporating temperature range of $-45^{\circ} \mathrm{C}$ to $-25^{\circ} \mathrm{C}$.

\section{Conclusion}

In order to determine which form of vapour compression refrigeration systems are suitable for application in different temperature ranges to maximise the energetic and economic efficiency, this paper established thermodynamic models for SSRS+E, TSRS and CRS, and conducted an energetic and economic analysis of it. Based on the results and preceding discussion, the following conclusions can be obtained:

1. In the theoretical analysis, due to the influence of more efficient inter-stage cooler, TSRS is superior to SSRS+E in system COP. Conversely in economic analysis, when the evaporating temperature is above $-25^{\circ} \mathrm{C}, \mathrm{SSRS}+\mathrm{E}$ is superior to TSRS in energy consumption, and the payback period of SSRS+E is in an acceptable range, especially when it runs longer to use.

2. Theoretical analysis shows that there is a cross-point of the COP curves between TSRS and CRS, where the corresponding evaporating temperatures of TSRS with R170/R717 CRS and R744/R717 CRS are $-48^{\circ} \mathrm{C}$ and $-52^{\circ} \mathrm{C}$, respectively. TSRS is superior to CRS in system COP when the evaporating temperatures are above the temperatures of the cross-points. Economic analysis shows that when the evaporating temperature is below $-45^{\circ} \mathrm{C}, \mathrm{R} 744 / \mathrm{R} 717 \mathrm{CRS}$ is superior to TSRS in energy consumption and refrigeration unit investment costs, which offers significant energetic and economic advantages.

3. SSRS+E is recommended for use above the evaporating temperature of $-25^{\circ} \mathrm{C}$. TSRS is recommended for use in the evaporating temperature range of $-45^{\circ} \mathrm{C}$ to $-25^{\circ} \mathrm{C}$, and $\mathrm{R} 744 / \mathrm{R} 717 \mathrm{CRS}$ is recommended for use below the evaporating temperature of $-45^{\circ} \mathrm{C}$.

\section{Notes on Contributors}

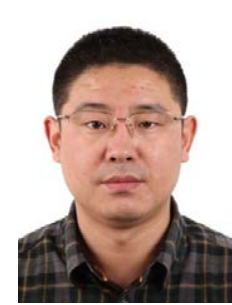

Dr Zhili Sun is an Associate Professor at the Department of Refrigeration and Cryogenic Engineering, Tianjin University of Commerce, People's Republic of China (TJCU). He graduated from Tianjin University, People's Republic of China and TJCU, respectively. His research interests include energy saving and optimisation of refrigeration system, scientific problems of equal mass flow distribution of twophase fluid and heat transfer enhancement technology.

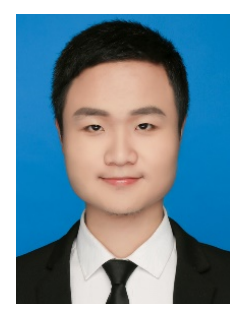

Mr Qi Cui obtained his B.Sc. degree in Energy and Power Engineering from TJCU in 2019. His research interests include energy saving, optimisation of refrigeration system, dehumidification technology, heat pump, and refrigerant substitution.

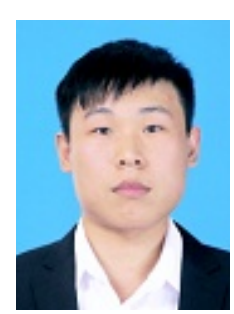

Mr Qingzhao Liu obtained his B.Sc. degree from TJCU in 2018. He is currently a postgraduate student at TJCU. His research interests include energy saving, optimisation of refrigeration system and refrigerant substitution.

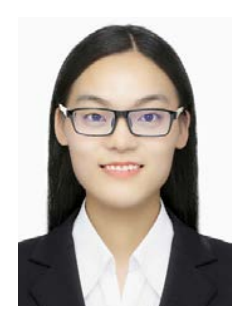

Ms Caiyun Wang is currently an undergraduate student at TJCU. Her research interests include energy saving, optimisation of refrigeration system and refrigerant substitution.

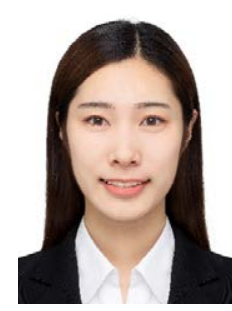

Ms Jiamei Li is currently an undergraduate student at TJCU. Her research interests include energy saving, optimisation of refrigeration system and refrigerant substitution.

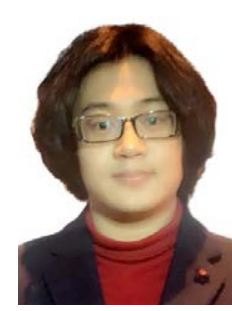

Mr LijieYang is currently an undergraduate student at TJCU. His research interests include energy saving, optimisation of refrigeration system and refrigerant substitution. 


\section{References}

[1] Abas N, Kalair AR, Khan N, Haider A, Saleem Z and Saleem MS (2018). Natural and synthetic refrigerants, global warming: A review. Renewable and Sustainable Energy Reviews, 90, pp. 557-569.

[2] Baakeem SS, Orfi J and Alabdulkarem A (2018). Optimization of a multistage vapor-compression refrigeration system for various refrigerants. Applied Thermal Engineering, 136, pp. 84-96.

[3] Bobbo S, Nicola GD, Zilio C, Brown JS and Fedele L (2018). Low GWP halocarbon refrigerants: A review of thermophysical properties. International Journal of Refrigeration, 90, pp. 181-201.

[4] Briley G C (2004). A history of refrigeration. ASHRAE Journal, 46(11), pp. 475-520.

[5] Choi S, Han U, Cho H and Lee H (2018). Review: Recent advances in household refrigerator cycle technologies. Applied Thermal Engineering, 132, pp. 560-574.

[6] Ciconkov R (2018). Refrigerants: There is still no vision for sustainable solutions. International Journal of Refrigeration, 86, pp. 441-448.

[7] Devecioğlu AG and Oruç V (2015). Characteristics of some new generation refrigerants with Low GWP. Energy Procedia, 75, pp. 1452-1457.

[8] Gullo P, Hafner A and Banasiak K (2018). Transcritical R744 refrigeration systems for supermarket applications: Current status and future perspectives. International Journal of Refrigeration, 93, pp. 269-310.

[9] Heath EA (2017). Amendment to the Montreal Protocol on Substances that Deplete the Ozone Layer (Kigali Amendment). International Legal Materials, 56, pp. 193-205.

[10] Kasaeian A, Hosseini SM, Sheikhpour M, Mahian O, Yan W and Wongwises S (2018). Applications of ecofriendly refrigerants and nanorefrigerants: A review. Renewable and Sustainable Energy Reviews, 96, pp. 91-99.

[11] Klein SA, Reindl DT and Brownell K (2000). Refrigeration system performance using liquidsuction heat exchangers. International Journal of Refrigeration, 23, pp. 588-596.

[12] Lemmon EW, Huber ML and Mclinden MO (2013). NIST standard reference database 23: Reference fluid thermodynamic and transport properties-REFPROP, Version 9.1. United States: National Institute of Standards and Technology.

[13] Liu J, Li Q, Wang F and Zhou L (2012). A new model of screw compressor for refrigeration system simulation. International Journal of Refrigeration, 35, pp. 861-870.
[14] Llopis R, Sánchez D, Sanz-Kock C, Cabello R and Torrella E (2015). Energy and environmental comparison of two-stage solutions for commercial refrigeration at low temperature: Fluids and systems. Applied Energy, 138, pp. 133-142.

[15] Luyben WL (2019). Refrigerant selection for different cryogenic temperatures. Computers \& Chemical Engineering, 126, pp. 241-248.

[16] Messineo A (2012). R744-R717 cascade refrigeration system: Performance evaluation compared with a HFC two-stage system. Energy Procedia, 14, pp. 5665.

[17] Patel V, Panchal D, Prajapati A, Mudgal A and Davies $P$ (2019). An efficient optimization and comparative analysis of cascade refrigeration system using $\mathrm{NH}_{3} /$ $\mathrm{CO}_{2}$ and $\mathrm{C}_{3} \mathrm{H}_{8} / \mathrm{CO}_{2}$ refrigerant pairs. International Journal of Refrigeration, 102, pp. 62-76.

[18] Polonara F, Kuijpers L and Peixoto R (2017). Potential impacts of the Montreal Protocol Kigali Amendment to the choice of refrigerant alternatives. International Journal of Heat and Technology, 35, S1-S8.

[19] Purohit N, Gupta DK and Dasgupta MS (2016). Effect of inter-stage pressure on the performance of a two stage refrigeration cycle using inter cooler. Energy Procedia, 90, pp. 171-178.

[20] Sawalha S, Piscopiello S, Karampour M, Manickam L and Rogstam J (2017) . Field measurements of supermarket refrigeration systems. Part II: Analysis of HFC refrigeration systems and comparison to $\mathrm{CO}_{2}$ trans-critical. Applied Thermal Engineering, 111, pp. 170-182.

[21] She X, Cong L, Nie B, Leng G, Peng H, Chen Y, Zhang X, Wen T, Yang H and Luo Y (2018). Energy-efficient and economic technologies for air conditioning with vapor compression refrigeration: A comprehensive review. Applied Energy, 232, pp. 157186.

[22] Steven Brown J and Domanski PA (2014). Review of alternative cooling technologies. Applied Thermal Engineering, 64, pp. 252-262.

[23] Wang B, Liu X, Shi W and Ding Y (2018). An enhanced rotary compressor with gas injection through a novel end-plate injection structure. Applied Thermal Engineering, 131, pp. 180-191.

[24] Wang B, Wu H, Li J and Xing Z (2009). Experimental investigation on the performance of $\mathrm{NH}_{3} / \mathrm{CO}_{2}$ cascade refrigeration system with twin-screw compressor. International Journal of Refrigeration, 32, pp. 13581365.

[25] Wang X, Yu J and Xing M (2015). Performance analysis of a new ejector enhanced vapor injection heat pump cycle. Energy Conversion and Management, 100, pp. 242-248. 